International Journal of Social Science And Human Research

ISSN(print): 2644-0679, ISSN(online): 2644-0695

Volume 05 Issue 02 February 2022

DOI: 10.47191/ijsshr/v5-i2-44, Impact factor-5.586

Page No: $712-717$

\title{
The Impact of Learner Agency and Self-Regulated Learning in EFL Classes
}

\author{
Mahbuba Rasulova ${ }^{1}$, Kevin Ottoson ${ }^{2}$ \\ ${ }^{1}$ Tashkent State University of Law \\ ${ }^{2}$ Nagoya Women's University
}

\begin{abstract}
Learners have a sense of "agency" when they feel they can influence the events and feel in control of different things occurring around them. This is an important sense for learners, making them more active participants in their learning. Every decision a learner makes, and action she or he takes, will impact the thinking, behavior or decisions of others. When learners can control their own learning, they exercise self-regulated learning (SRL), which is crucial in becoming a lifelong learner. McIenrney (2008) described SRL as "self-generated thoughts, feelings, and actions in order to attain educational goals" (p. 374). This study focuses on case studies of three English language learners at a language school in Tashkent, Uzbekistan. Case study data were generated through a series of six in-depth, informal interviews conducted in English over four months. Triangulated data revealed a bond between learner agency and self-regulated learning as more agentic learners tend to use different kinds of self-regulated strategies. In contrast, less agentic ones appear more passive when it comes to employing self-regulating strategies in their learning process. Finally, suggestions to facilitate learner agency and self-regulated learning in the language-learning classroom are provided.
\end{abstract}

KEY WORDS: Agency Self-regulation Motivation Self-discipline

\section{INTRODUCTION}

Successful language learning is crucially intertwined with the activity and initiative of the learner (Van Lier 2008). However, learners should hold a sense of agency - a belief that their behavior can make a difference to their learning in a particular setting, before engaging their agentic resources and choosing how to exercise their agency in that setting (Mercer, 2012). Mercer (2011a) stated that lies in the latent potential to engage in self-directed behavior. However, how and when that potential is used depends on a learner's sense of agency involving their belief systems and the control parameters of motivation, affect, and self-regulatory skills. A learner's ability to effectively self-regulate can greatly impact one's performance (Zimmerman, 2008).

Self-regulated learning (SRL) is defined as "self-generated thoughts, feelings, and actions in order to attain educational goals that include such processes as planning and managing time; attending to and concentrating on instruction; organizing, rehearsing, and coding information; establishing a productive work environment; and using social resources effectively" (McInerney, 2012, p. 374). Self-regulated learners are cognizant of their strengths and weaknesses to easily adapt to learning situations by using conducive learning strategies. In contrast, less self-regulated learners tend to lack of those abilities and have more limited repertoire of strategies which could lead to academic failure (Hartley \& Bendixen, 2001).

In this study, the focus is on case studies of three participants, two females and one male, learning English at one of the language schools in Uzbekistan. Case study data were generated through a series of six in-depth, informal interviews conducted in English over four months. A case study enables the researcher to collect data from the person-in-context. This detailed data can provide a researcher the chance to gain holistic understanding of an individual. Thus, the researcher can provide a detailed exploration of a bounded system (Creswell, 2013). This study aimed to provide insights into complex aspects of a learner's experience and psychology. Regarding the definitions of learner agency and self-regulated learning, a case study would be conducive to generating data to provide rich insights to understand how agency and self-regulated learning impact learners. The data were analyzed based on the grounded theory approach to answer the following research questions:

1. What self-regulation strategies do learners use in EFL classes?

2. How does learner agency impact learner performance in EFL classes?

\section{LITERATURE REVIEW}

Agency is often stated as the most ubiquitous construction in the educational field, although it is not exactly defined. Agency is mostly considered as a result of the educational process, yet it is rarely investigated systematically in educational research (Rainio, 


\section{The Impact of Learner Agency and Self-Regulated Learning in EFL Classes}

2008; Barton \& Tan, 2010). Learner agency lies in the feeling of ownership and the sense of control that students have in their learning process. In a sense, the more agency is given to students in the classroom, the more responsible and confident they become, leading them to make a difference in their learning. Most scholars might confuse learner agency because of it is relation to concepts of learner autonomy, self-directed learning, self-learning, and self-regulated learning (Gao, 2021).

In her empirical study, Larsen-Freeman (2019) revealed the interdependence between structure and agency using Complex Dynamic Systems Theory. Agency is characterized as relational, emergent, spatially and temporally, achievable, changeable, and multidimensional. These characteristics of agency will be described in more detail.

\section{Agency is relational}

Agency cannot be inhered in a person. Instead, it is "interpellated from the self-organizing dynamic interaction of factors internal and external to the system, persisting only through their constant interaction with each other" (Larsen-Freeman, 2019, p. 65). Therefore, a sense of agency is relational. Ellis (2019) also suggested that agency is always related to affordances, which are the opportunities for action or interaction offered to learners in the context; it cannot be separated from them.

\section{Agency is emergent}

Agency appears when spontaneous activity is joined to the world, creating a coordinative structure, which is "embodiments of the principle of functional equivalence” (Kelso, 2016, pp. 491-492). Similarly, Miller (2014) posited that learners' agentic capacity could be clearly understood in developing relationships with others and the world.

\section{Agency is spatially and temporally situated}

Emirbayer and Mische (1998) proposed agency appears influenced by the past, engagement with the present, and oriented to the future. As Mercer (2012) suggested, agency includes people's ongoing life, as well as their past and future.

\section{Agency can be achieved}

Agency is not a power that individuals have; rather, it is something they can achieve by utilizing the environment, not simply in an environment (Biesta \& Tedder, 2007, Miller, 2016). Thus, reciprocal relationships of individual efforts, available resources, and contextual and structural factors lead to agency achievement. (Biesta \& Tedder, 2007).

\section{Agency changes through iteration and co-adaptation}

Larsen-Freeman (2019, p. 67) suggested that "the starting point is initial condition is always different, and the consequences are the system's mutability". Repeating something in a different way, not the same as the original, creates space to use one's language resources, make different meanings, position oneself as desired, and express identity the way they wanted (Deleuze, 2004).

\section{Agency is multidimensional}

Agency is not only about behavior (Larsen-Freeman, 2019); rather, it means having the ability to designate relevance and significance related to things and events (Lantolf \& Thorne, 2006). In Mercer's work (2012), the multidimensional nature of agency is seen to be intertwined with participants' emotions, self-beliefs, beliefs about language learning, and motivation, which are intrapersonal factors.

Drawing on the diverse nature of agency, Larsen-Freeman (2019, p. 73) defined agency as "not something possessed, but achieved by an individual, orienting to different affordances of the social and the material worlds. Agency changes through iteration and adaptation. It is multidimensional and heterarchical". Much in the same vein, Mercer (2012) stated that learner agency is composed of two main dimensions which "cannot meaningfully be separated" (p. 42). Firstly, individuals hold a sense of agency, that is, how agentic they are in general and in particular contexts. Secondly, individuals are involved in their agentic behavior in which they have an option to choose the way of exercising their agency through participation and action, or through "deliberate non-participation" and "non-action" (Mercer, 2012, 42). Therefore, agency is not always observable; rather, it can include nonvisible behaviors, beliefs, thoughts, and feelings that can be fully understood in different contexts and affordances. The findings of Mercer's work (2011a) revealed that agency cannot be conceived of as a single monolithic variable; rather it is probably best understood as a complex, dynamic system including various interrelated components. She suggested that "[1] earner agency exists as latent potential to engage in self-directed behavior but how and when it is used depends on a learner's sense of agency involving their belief systems, and the control parameters of motivation, affect, metacognitive/self-regulatory skills, as well as actual abilities and affordances, actual and perceived, in specific setting” (Mercer, 2011a, p. 435).

In another paper, Mercer (2012) argued that agency is conceived of as being situated, "beyond contextual situation" and manifests itself in one "salient" dimension, belief systems, of people's agentic system. She claimed that agency is contextually, interpersonally, temporally, and intrapersonally situated. Situations and sociocultural or educational contexts should be examined more deeply beyond "superficial monolithic conceptualizations" (p.57). The findings showed that agency is also conceived as contextually situated in an "interpersonal sense in relation to other individuals, not only as interactional partners but also in respect to co-evolving and collective notions of agency" (Mercer, 2012, p. 55). If agency is viewed holistically, it is considered as temporally situated and linked to the changing nature of one's developing life history (Mercer, 2012). This includes their experiences in the past and present, and their prospective goals and expectations. In terms of belief systems, learner beliefs are likely to play a major role in their agentic system. It is shown that learners' beliefs, self, and mindset, are tightly intertwined with each other. 


\section{The Impact of Learner Agency and Self-Regulated Learning in EFL Classes}

Gao (2021) assumed that learner agency could be a new way to put all established ideas into one and claimed that those concepts are interrelated. However, the learner agency can be regarded as the root of them all. "Agency is a much more holistic concept than autonomy, as agents are seen as embodied, thinking, feeling, social beings with unique histories and identities who pursue interests and goals at particular times and places."

The notion of self-regulation is interrelated with the assumption that learners exercise their agency by consciously controlling and regulating themselves in the learning process. Regarding the boundaries of their capabilities, along with constraints and affordances in their environment, learners can exercise agency by setting goals and making choices to reach their goals, deciding how intense effort they need to put into engaging in a task, and choosing how long they can persist if they fail in completing the task (Winne \& Hadwin, 2008). Or more succinctly, "what people think, believe, and feel affects how they behave" (Bandura, 1986, p. 25). Thus, it is important to have a better understanding about what learners believe about themselves their abilities as they can inform us about their agency. This study aims to better understand what learners believe about themselves and how they behave in regard to regulating their own learning.

\section{METHODOLOGY}

Through the case studies of three participants, two females and one male, learning English at a language school in Uzbekistan, the researcher aimed to gain a holistic understanding of the learners' use of agency and self-regulation. Although the analysis concentrates on their agency and self-regulated learning behaviors, it should be borne in mind that as a holistic being, their agency and self-regulated learning behaviors is interrelated to the other aspects of their life.

Case study data were generated through six in-depth, informal interviews conducted in English over four months. The data were analyzed based on the grounded theory approach, which preserves the holistic and situated nature of the data (Charmaz, 2006). Specifically, this study sought to answer the following research questions:

1. What self-regulation strategies do learners use in EFL classes?

2. How does learner agency impact learner performance in EFL classes?

This study was conducted at one of the many language schools in Tashkent, Uzbekistan. Most of the language schools in the area have experienced teachers who can conduct the classes in an interesting way, but there are some schools in which the quality of the lessons are not very good. This study used a random sampling as due to the convenient location of the language school. The school was in a location that allowed easier contact with the research participants.

The research participants are Dilfuza, Lola and Otabek. Dilfuza and Lola both are in the intermediate level group, and Otabek is in the IELTS group. Upon receiving their consent form, data was collected from the participants' journal entries, the researcher observations, and interviews with the participants to provide a triangulated analysis of the data. The interviews were held in person and all of them were digitally recorded so that they could be transcribed verbatim later. Pseudoynms were assigned to all the names in the transcriptions to protect their identities. See Table 1 for the background of the participants.

Table 1: Background of participants

\begin{tabular}{lllll}
\hline$\#$ & Name & Gender & Age & Class \\
\hline 1 & Dilfuza & Female & 16 & Intermediate \\
2 & Lola & Female & 15 & Intermediate \\
3 & Otabek & Male & 17 & IELTS \\
\hline
\end{tabular}

\section{FINDINGS}

From the observations, Dilfuza appeared to be a punctual, consistent, organized, and conscientious student. She was always ready for the classes, did all homework given by her teacher and participated in the classes very actively. Her performance was consistent throughout the course. Dilfuza's answers to the questions related to self-regulated learning strategies in the interviews confirmed the assumptions about her.

"I think I am self-regulated learner, because I always try to learn English well, do my homework on time. Also, I try to speak English in classes because I know if I am shy speaking...to speak in front of my friends (...) my classmates, I can't learn English. When we finish our classes, I with my friends do different tasks together. I think it is good chance for me and for them, too. Because we can share our ideas with each other (...) I always make plans what to do, I can say they are my short -term plans and I always tick them when I have done them."

Her agency is interrelated with the affordances and constraints emerged during the classes. Dilfuza strongly believes the importance of speaking and the need to have contact with other students whose language levels are higher than her are very important. It thus becomes apparent how agentic she can be in those situations.

"There are some students in our group and other students in other groups whose English is better than me. They speak so well (...) so fluently. I always try to get together with them to have a conversation or sometimes we do debate on one topic. I know I might not have enough vocabulary to express my ideas during the debates, but I never give up in those situations. I try to connect my speech, anyway. I know if I stop, I might lose my motivation to learn. I know I am very motivated!” 


\section{The Impact of Learner Agency and Self-Regulated Learning in EFL Classes}

Another participant, Lola, seemed to be a struggling learner from the beginning. She frequently missed the classes and assignments. In group discussions, she rarely spoke although she had a chance to speak. Moreover, she seemed to be shy to speak in front of others. That might be the big hindrance for her to show full capacity. During the interview she said:

"I am interested in English...so I came here to learn English. I always [regulate myself while learning English. I always make rigid plans. However, sometimes I do not follow them]. I know this is not good. I should do all my plans. (Moreover], I am a bit shy (to speak in front of my classmates] because they know English better than me. I am afraid to make mistakes.

As for Lola's agency, it is temporally situated as it emerges only in affordances; she was able to show her agency only when she had a suitable moment. She could not overcome constraints that cropped up in the lesson flow. She also connected her agency to her self-beliefs:

“My English is not very good. I can't speak well (although] I practice speaking a lot at home... I practice speaking alone, because I am afraid making mistakes. I always have problem to understand some grammar topics like conditional clauses...my teacher explained it five times...I didn't understand well."

Another participant, Otabek, is different from the other two participants. He seemed to be a diligent, consistent, motivated, and hard-working learner as he showed that he has a self-regulation over his behavior. He said:

"I always strive to achieve my goals which are not only related to language learning, but also the ones related to other aspects of my life. In pursuit my goals, I control...regulate myself to get every single thing done on time. Well, I always plan what I need to, and then set appropriate goals after which I lay out some strategies. Then I check my performance, like how I am using my knowledge, how I can be active in the classes, what are my weak points and how I can handle these issues, such kind of stuff. To be honest, these strategies [being self-regulated over one's behavior] help me a lot".

In terms of agency, Otabek is a very agentic learner while learning any foreign language. His agency is contextually, interpersonally and intrapersonally situated as his agency varies in different contexts, when he communicates with different people. Also, he is confident in his physical and cognitive capacity to act, and he is highly motivated:

"Undoubtedly, I consider myself very motivated person that I can do everything if I put all my efforts in it. Here, at school, I love communicating with students, of course, in English. We often have debates and discussions in our classes and I think this is very good opportunity for me to practice English, to use new words and collocations I have learnt, and to show my ability (laughs)".

In sum, all participants described their agentic behavior and self-regulation strategies. The participants demonstrated agency and self-regulation to varying extents. Thus, self-regulated strategies, such as setting goals, utilizing some strategies, active performance, and agency, have a considerable impact on language performance. The interview data highlights the importance of overcoming constraints which negatively affect negatively one's ability to become a self-regulated and highly agentic learner.

\section{DISCUSSION}

Triangulated data revealed a bond between learner agency and self-regulated learning as more agentic learners tend to use different kinds of self-regulated strategies. Meanwhile, the less agentic one seemed a bit passive to employ those strategies in their learning process. According to Zhang (2010), those who have a strong motivation to learn and good self-regulatory skills tend to benefit from self-regulation strategies in or out of the classroom. Those who are less motivated and have difficulties with self-regulation are more likely to be shy or frustrated.

Dilfuza and Otabek have intrinsic motivation that enables them to take some actions to self-improvement or make a difference in their learning. All of their actions proved to be meaningful and integrative steps towards their goals of becoming good users of the target language. Their active engagement in classes and activities resulted from thoughtful planning, good organization skills, and self-discipline, which supported successful learning outcomes.

In contrast, Lola had some difficulties in understanding some points during the classes. Therefore, she seemed to have a barrier in getting engaged in tasks and activities. Moreover, her uncertainties towards her language learning goals and her emotional situation, being shy, inhibited her from showing her agency and her performance.

Having investigated the data, the following suggestions could help alleviate student anxiety and optimize learning conditions:

- To maximize student-student interaction, students should be placed in classes according to their language proficiency levels so that all students feel secure while speaking English, and also this might help to overcome a fear of making mistakes. Having students slightly higher than one's ability can be quite motivating as is evident from Dilfuza's experience.

- Instructors should aim to create learning environments where learners are not overly concerned with making mistakes. Learners who have less fear of failure are more capable of self-regulating their own learning (Shirkhani \& Ghaemi, 2011).

- To improve student-instructor interaction, instructors should provide a timely, clear, and structured assessment of student performance.

- Students should be involved in their assessment. Part of this assessment process should allow for students to set goals for their own learning, decided how to achieve it, monitor their progress, assess their progress, and continue to set new goals (Schunk, 2001). 


\section{The Impact of Learner Agency and Self-Regulated Learning in EFL Classes}

- If needed, instructors should encourage or offer extra tutoring so that struggling students could receive both mental and practical help, which might increase their motivation, agency and self-discipline. This practical help can include strategies to develop more self-regulated learning.

\section{CONCLUSION}

By conducting a case study of three students enrolled in in-person General English and Academic IELTS courses at a language school, this study investigated what self-regulated strategies learners use to make a difference in their learning and how their agency impact their performance. Both learners who were more agentic in nature employed more self-regulated learning strategies. While the less agentic learner took a more passive approach and struggled to carry out self-regulated learning strategies.

It should be noted that this study is fairly limited in scope, this study has only three participants and due to a rather small group and the case study methodologies it employs, the findings may not be generalized to all contexts. The short duration of the research and limited contact with focal students, many variables were not investigated that might contribute to the clearer results. Further research should aim to include a larger group of participants, different age groups and personalities, cultural backgrounds, and educational histories. Much of what we know about self-regulation is informed from theorizing and research in Western contexts (McInerney, 2012). The same can be argued about agency. Thus, future investigations can provide better understanding of our diverse learners and effective ways to foster agency and self-regulated learning.

\section{REFERENCES}

1) Bandura, A. (1986). Social foundations of thought and action: A social cognitive theory. Prentice Hall.

2) Barton, A.C., \& Tan, E. (2010). We be burnin'! Agency, identity, and science learning. The Journal of the Learning Sciences, 19(2), 187-229

3) Biesta, G., \& Tedder, M. (2007). Agency and learning in the lifecourse: Towards an ecological perspective. Studies in the Education of Adults, 39, 132-149.

4) Charmaz, K. 2006. Constructing grounded theory. Sage.

5) Creswell, J. W. (2013) Qualitative inquiry and research design: Choosing among five approaches ( $3^{\text {rd }}$ ed.). Sage.

6) Mahbuba, R. (2022). THE ROLE OF STUDENT-STUDENT INTERACTION IN EFL CLASSROOMS. Eurasian Journal of Social Sciences, Philosophy and Culture, 2(2), 63-66.

7) Deleuze, G. (2004). Difference and repetition. Continuum Publishing Group.

8) Emirbayer, M., \& Mische, A. (1998). What is agency? American Journal of Sociology, 103, 962-1023.

9) Ellis, N. C. (2019). Essentials of a theory of language cognition. Modern Language Journal, 103 (Supplement 2019), 3960.

10) Gao, $X$ (2021, December 10). An Introduction to Learner Agency. Oxford University Press ELT. https://oupeltglobalblog.com/2021/12/10/introduction-learner-agency/

11) Hartley, K., \& Bendixen, L. D. (2001). Educational research in the Internet age: examining the role of individual characteristics. Educational Researcher, 30 (9): 22-26.

12) Kelso, J. S. (2016). On the self-organizing origins of agency. Trends in Cognitive Science, 20, 490-499.

13) Mahbuba, R. (2022). THE ROLE OF STUDENT-STUDENT INTERACTION IN EFL CLASSROOMS. Eurasian Journal of Social Sciences, Philosophy and Culture, 2(2), 63-66.

14) Lantolf, J. P., \& Thorne, S. (2006). Socioculturaltheoryand the genesis of second language development. Oxford University Press.

15) Larsen-Freeman, D. (2019). On a language learner agency: A complex dynamic systems theory perspective. The Modern Language Journal, 103, 62-79.

16) McInerney, D. M. (2012). The motivational roles of cultural differences and cultural identity in self-regulated learning. In D. H. Schunk, \& B. J. Zimmerman (Eds.), Motivation and Self-regulated Learning. Theory, Research, and Applications $\left(3^{\text {rd }}\right.$ ed). Lawrence Erlbaum Associates.

17) Mercer, S. (2011a). Understanding learner agency as a complex dynamic system. System 39(4), 427-436.

18) Mahbuba, R. (2022). IMPLICATING TASK-BASED LEARNING IN TEACHING LEGAL ENGLISH. Eurasian Journal of Social Sciences, Philosophy and Culture, 2(2), 55-62.

19) Mercer, S. (2012). The complexity of learner agency. Apples-Journal of Applied Language Studies, 6(2), 41-59.

20) Miller, E. R. (2014). The language of adult immigrants: Agency in the making. Multilingual Matters.

21) Miller, E. R. (2016). The ideology of learner agency and the neoliberal self. International Journal of Applied Linguistics, 26, 348-365.

22) Rasulova, M. (2021). Examining learner agency of first-year English majors in Japanese university online EFL classes. 南山言語科学=Nanzan studies in language science (16), 1-26. 
23) Rainio, A.P. (2008). From resistance to involvement: Examining agency and control in a playworld activity. Mind, Culture, and Activity, 15(2), 115-140.

24) Schunk, D. H. (2001). Self-regulation through goal setting. ERIC Clearninghouse on Counseling and Student Service, University of North Carolina at Greensboro.

25) Mahbuba, R. (2022). THE ROLE OF STUDENT-STUDENT INTERACTION IN EFL CLASSROOMS. Eurasian Journal of Social Sciences, Philosophy and Culture, 2(2), 63-66.

26) Shirkhani, S. \& Ghaemi, F. (2011). Barriers to self-regulation of learning: Drawing on Bandura's ideas. Procedia-Social and Behavioral Sciences, 29, 107-110.

27) Van Lier, L. (2008). Agency in the classroom. In J. P. Lantolf, \& M.E. Poehner (Eds.), Sociocultural theory and the teaching of second languages. Equinox.

28) Winne, P. H., \& Hadwin, A. F. (2008). The weave of motivation and self- regulated learning. In D. H. Schunk, \& B. J. Zimmerman (Eds), Motivation and Self-regulated Learning. Theory, Research, and Applications. Lawrence Erlbaum Associates.

29) Mahbuba, R. (2022). IMPLICATING TASK-BASED LEARNING IN TEACHING LEGAL ENGLISH. Eurasian Journal of Social Sciences, Philosophy and Culture, 2(2), 55-62.

30) Zhang, J. (2013). Learner agency, motive, and self-regulated learning in an online ESL writing class. IALLT Journal of Language Learning Technologies, 43(2), 58-81.

31) Zimmerman, B. J. (2001). Theories of self-regulated learning and academic achievement: An overview and analysis. In B. J. Zimmerman, \& D. H. Schunk (Eds.), Self-regulated Learning and Academic Achievement. Theoretical Perspectives. Erlbaum.

32) Zimmerman, B. J. (2008). Investigating self-regulation and motivation: Historical background, methodological developments, and future prospects. American Educational Research Journal, 45, 166-183.

33) Rasulova, M. (2021). Examining learner agency of first-year English majors in Japanese university online EFL classes. 南 山言語科学= Nanzan studies in language science, (16), 1-26.

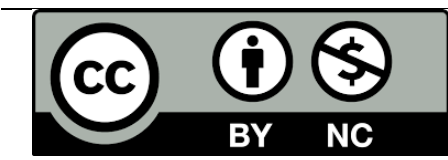

There is an Open Access article, distributed under the term of the Creative Commons Attribution - Non Commercial 4.0 International (CC BY-NC 4.0)

(https://creativecommons.org/licenses/by-nc/4.0/), which permits remixing, adapting and building upon the work for non-commercial use, provided the original work is properly cited. 